\title{
In situ analysis of hydration and ionic conductivity of sulfonated poly(ether ether ketone) thin films using an interdigitated electrode array and a nanobalance
}

\author{
Hendrik Wulfmeier ${ }^{1}$, Niklas Warnecke ${ }^{1}$, Luca Pasquini ${ }^{2}$, Holger Fritze ${ }^{1}$, and Philippe Knauth ${ }^{2}$ \\ ${ }^{1}$ Institute of Energy Research and Physical Technologies, Clausthal University of Technology, \\ 38640 Goslar, Germany \\ ${ }^{2}$ Aix-Marseille University, CNRS, Madirel (UMR 7246), site St Jérôme, \\ Marseille, 13013, France
}

Correspondence: Hendrik Wulfmeier (hendrik.wulfmeier@tu-clausthal.de)

Received: 19 October 2021 - Revised: 4 January 2022 - Accepted: 15 January 2022 - Published: 23 February 2022

\begin{abstract}
Proton-conducting polymers, such as sulfonated poly(ether ether ketone) (SPEEK), are of great industrial interest. Such proton exchange membranes show high tendencies for water and water vapor uptake. The incorporation of water not only leads to mass and dimensional changes, but also to changes in conductivity by several orders of magnitude. Both properties highly impact the potential application of the materials and, therefore, have to be known precisely. As hydration is diffusion controlled, thin films may behave differently to bulk specimens. However, the determination of small mass changes occurring in thin-film samples is very challenging.

In this work, a new measurement setup is presented to simultaneously characterize the mass change and the conductivity of thin polymer films. The mass change is measured by resonant piezoelectric spectroscopy (RPS) with a nanobalance, which is based on high-precision piezoelectric resonators operating in thickness-shear mode (TSM). The mass resolution of this nanobalance is $\pm 7.9 \mathrm{ng}$. Electrochemical impedance spectroscopy and an interdigitated electrode array are used for conductivity measurements. The approach is validated by comparing two SPEEK films with different degrees of sulfonation (DS). The relative humidity (RH) in the measurement setup was changed stepwise within the range $\sim 2 \%<\mathrm{RH}<\sim 85 \%$. For both material compositions, $\mathrm{DS}=0.5$ and $\mathrm{DS}=0.9$, the mass uptake, the hydration number and the proton conductivity are presented and discussed depending on $\mathrm{RH}$.

This newly designed experimental setup allows for in situ characterization of the properties mentioned above; it can monitor not only the data for the stationary state, but also the dynamics of the hydration. To the authors' knowledge this is the first simultaneous and in situ measurement device for simultaneously sensing mass and conductivity change due to hydration of polymeric thin-film materials.
\end{abstract}

1

Ionomers are fascinating polymeric materials, in which electrolytic groups, such as sulfonic acid (Alberti et al., 2001; Jones and Roziere, 2001; Kreuer, 1997; Kreuer et al., 2004; Li et al., 2003) or quaternary ammonium (Arges and Zhang, 2018; Bauer et al., 1990; Couture et al., 2011; Elattar et al., 1998; Sun et al., 2018; Varcoe and Slade, 2005), are anchored on the polymer chains and dissociated counter-ions can mi- grate in hydrated nanometric channels inside the hydrophobic polymer matrix. The resulting ion-conducting materials are very useful for many applications, including acid-base or humidity sensors (Alberti and Casciola, 2001; Ruzimuradov et al., 2018), water purification (Bauer et al., 1990) or separation membranes for electrochemical energy technologies, such as proton exchange membrane (PEM) (Alberti et al., 2001; Mehta et al., 2003) or anion exchange membrane (AEM) fuel cells (Sun et al., 2018; Varcoe et al., 2014). The 
proton conductivity of PEM can be tuned widely by the synthesis approach, including hybrid organic-inorganic materials (Di Vona et al., 2007, 2008a), polymer blends (Kerres, 2001; Maier and Meier-Haack, 2008), or composite solid electrolytes (Alberti and Casciola, 2003; Di Vona et al., 2008b).

Given the particular conduction mechanism of ionomers, the hydration properties are particularly important (Alberti et al., 2008; Kopitzke et al., 2000; Zawodzinski et al., 1993). There exists a strong correlation between water uptake and proton conductivity of proton exchange polymers (Di Vona et al., 2008a; Kreuer et al., 2004; Zawodzinski et al., 1993). This relation can be formalized by defining effective ion mobility that can be linked with other phenomenological membrane parameters, such as tortuosity or percolation thresholds (Knauth et al., 2011, 2021; Knauth and Di Vona, 2012; Peckham et al., 2008). However, the hydration and ion conductivity are generally measured ex situ and in separate experimental setups, and it is not always evident how to reconcile these properties. The hysteresis of water uptake and ion conductivity during heating and cooling or dehydration and rehydration cycles (Alberti et al., 2008) or conductivity decay processes (Casciola et al., 2006) are for example well-known but not completely understood phenomena, related also to the so-called Schröder paradox (Eikerling and Berg, 2011; Freger, 2009; Kreuer, 2013). For these reasons, the design of an experimental procedure allowing an in situ determination of water uptake and conductivity of ionomers under identical conditions is extremely worthwhile.

Nanogravimetry using temperature-stable piezoelectric resonator materials is a powerful method for the determination of small mass changes at variable temperatures and atmospheres. Thickness-shear mode (TSM) resonators based on langasite ( $\mathrm{La}_{3} \mathrm{Ga}_{5} \mathrm{SiO}_{14}$, LGS) (Fritze and Tuller, 2002; Seh et al., 2007) can be used for the in situ analysis of thin films in many fields, such as non-stoichiometry determination at high temperatures (Schröder et al., 2018), chemical vapor deposition (Grate, 2000; Habuka and Tanaka, 2013), aerosol mass detection (Czanderna and Lu, 1984), electrochemical deposition (Leppin et al., 2021), mass changes in polymers (Marx, 2006) or humidity control (PascalDelannoy et al., 2000). They measure very small mass changes in a material deposited on the resonator by the shift of the resonance frequency (Lucklum and Eichelbaum, 2006; Johannsmann, 2015).

In this work, we design a new experiment for the in situ determination of water uptake (WU) and proton conductivity as a function of temperature and relative humidity based on a temperature-controlled air-tight chamber containing a mass-sensitive langasite resonator and a conductivity probe with interdigitated electrodes. To validate the technique, we investigate a particularly well-known ionomer, sulfonated poly(ether ether ketone) (SPEEK) (Bauer et al., 2000; Di Vona et al., 2009; Kaliaguine et al., 2003; Xing et

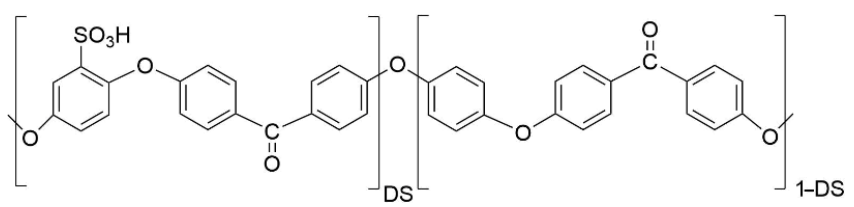

Figure 1. Structural formula of SPEEK.

al., 2004; Zhong et al., 2007), prepared by drop coating in thin-film form on the analysis platform.

The conductivity and WU data are obtained as a function of temperature and relative humidity $(\mathrm{RH})$ and discussed in dependence on the polymer's degree of sulfonation (DS).

\section{Experimental}

\subsection{SPEEK preparation}

Sulfonated poly(ether ether ketone) (SPEEK) is prepared by reaction of PEEK polymer (Victrex) with concentrated sulfuric acid at $50^{\circ} \mathrm{C}$. The reaction time determines the DS of the final ionomer, which is defined as the number of sulfonic acid groups per repeat unit of the polymer according to the structural formula represented in Fig. 1.

The product is precipitated in ice water and thoroughly washed to neutral $\mathrm{pH}$ in dialysis bags using ice-cold water. The detailed procedures can be found in the references (Kaliaguine et al., 2003; Di Vona et al., 2009).

In this work, two SPEEK samples with a DS of 0.9 or 0.5 are used. The DS is measured by acid-base titration and NMR spectroscopy (Kaliaguine et al., 2003). These DS values correspond to ion exchange capacity (IEC) values of 2.5 and $1.5 \mathrm{meq} \mathrm{g}^{-1}$, respectively. The pure SPEEK powders are dissolved in dimethylsulfoxide (DMSO) to obtain a solution with sufficient viscosity that can be drop-coated on the langasite resonator and the conductivity probe (Figs. 2 and 3). The polymer thin films are dried at $80^{\circ} \mathrm{C}$ during $12 \mathrm{~h}$; they have a typical thickness of a few micrometers.

Film and electrode (see below) dimensions are characterized by tactile surface profilometry (Ambios XP-2, USA). The substrate thickness is measured by an inductive precision indicator (Mahr Extramess 2001, Germany).

\subsection{Nanobalance}

Y-cut LGS TSM resonators are chosen as a nanobalance since their resonance frequency shows a very low temperature dependence near room temperature of a few $\mathrm{Hz} \mathrm{K}^{-1}$ only. Single crystalline $5 \mathrm{MHz}$ LGS resonator blanks (SICCAS, P.R. China, diameter $10 \mathrm{~mm}$, thickness $\sim 270 \mu \mathrm{m}$ ) are coated on both sides with keyhole-shaped $\mathrm{Pt}_{0.8} \mathrm{Rh}_{0.2}$ electrodes (diameter $5 \mathrm{~mm}$, thickness $\sim 200 \mathrm{~nm}$ ) to enable piezoelectric excitation of the resonators (Fig. 2). The electrodes are applied by pulsed laser deposition using a $\mathrm{KrF}$ excimer laser (Lambda Physics CompEX 205, Germany) operating 

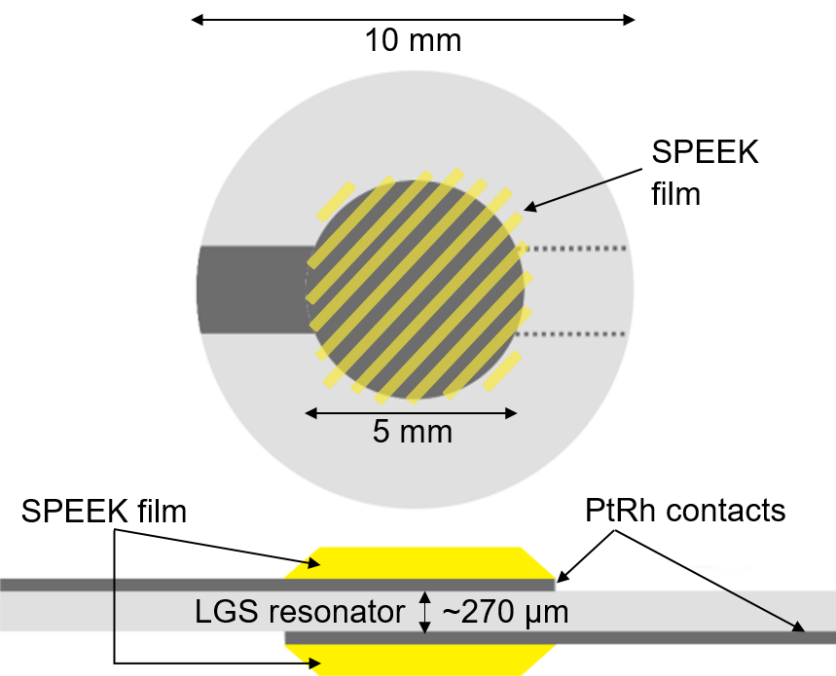

Figure 2. Scheme of the langasite resonator with electrodes and SPEEK films for hydration measurements. Note that the SPEEK film masses are detected with the nanobalance as well. See Sect. 3.2 for details.

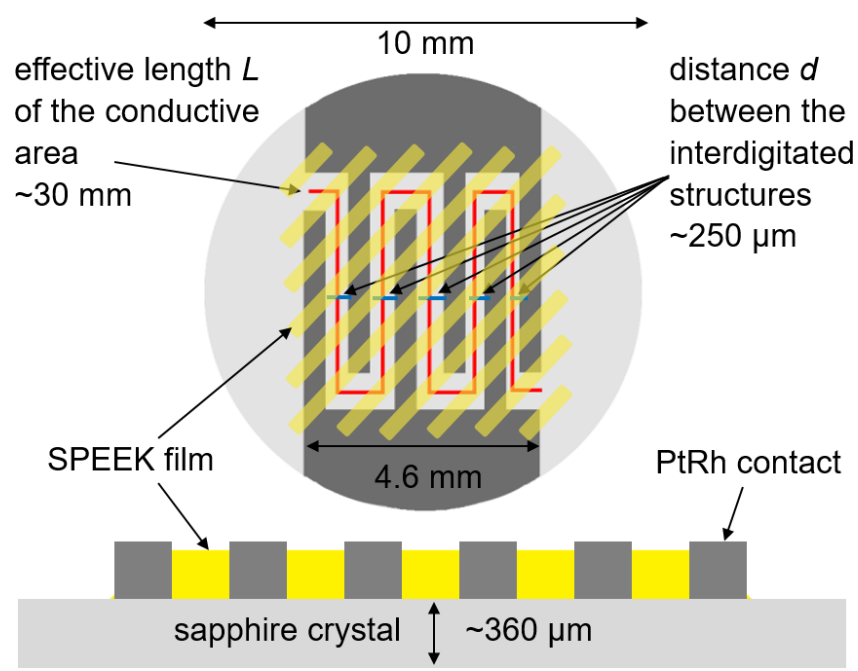

Figure 3. Scheme of the prepared sapphire crystal for proton conductivity measurements.

at a wavelength of $248 \mathrm{~nm}$. Deposition parameters include a base pressure of $1 \times 10^{-6}$ bar, a pulse energy of $350 \mathrm{~mJ}$ and a pulse repetition rate of $30 \mathrm{~Hz}$.

The SPEEK films are applied to both electrodes by drop coating and cover them largely. The average film thicknesses are $1.5 \mu \mathrm{m}$ for $\mathrm{DS}=0.9$ and $7.2 \mu \mathrm{m}$ for $\mathrm{DS}=0.5$. The nanobalance is coated on both sides to avoid bending stresses which might impact the resonance frequency. Furthermore, film surface area and sample mass are increased by a factor of 2 and, thus, the expected signal as well.

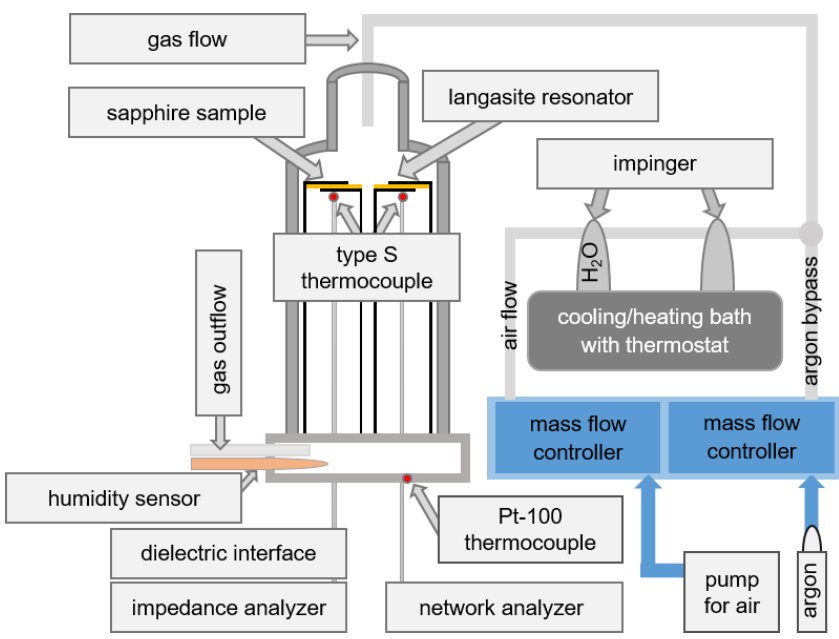

Figure 4. Scheme of the experimental setup.

\subsection{Conductivity probe}

High-ohmic single-crystalline sapphire substrates (SITUS Technicals GmbH, Germany) with $10 \mathrm{~mm}$ in diameter and about $360 \mu \mathrm{m}$ in thickness (Fig. 3) are contacted with interdigitated Pt electrodes applied by mesh printing (platinum paste no. 64120410, Ferro Corp., USA; mesh size $400 \mu \mathrm{m}$ ). The resulting electrodes show a thickness of $(2.4 \pm 0.2) \mu \mathrm{m}$. Finger and gap widths are approximately 500 and $250 \mu \mathrm{m}$, respectively. The length of the fingers is approximately $5 \mathrm{~mm}$. This results in an effective length $L$ of the conductive area of approximately $30 \mathrm{~mm}$. The entire interdigitated structure is drop-coated with SPEEK films of about $1.2 \mu \mathrm{m}$ (range $0.8-1.7 \mu \mathrm{m}$ for $\mathrm{DS}=0.5$ ) and $1.1 \mu \mathrm{m}$ (range $0.8-1.4 \mu \mathrm{m}$ for $\mathrm{DS}=0.9)$.

\section{Description of the in situ hydration measurement device}

\subsection{Sample chamber and control of humidity}

A scheme of the experimental setup used for the in situ conductivity and hydration measurements is shown in Fig. 4. The sample holder is placed in an air-tight quartz glass tube to enable humidity control. Nanobalance and conductivity probe are installed in an insulating quartz glass sample holder manufactured by ultrasonic milling (dama USF400, Switzerland). In order to realize identical thermal and atmospheric conditions, both samples are installed at the same height and at a close lateral distance of $5 \mathrm{~mm}$. The whole setup is inserted in a vertical tube furnace (Gero RO 50-250/13, Germany). To minimize temperature fluctuations during the measurement, the sample temperature is kept at $(29.9 \pm 0.6)^{\circ} \mathrm{C}$, which is slightly above room temperature: $(25.2 \pm 2.7){ }^{\circ} \mathrm{C}$. The sample temperature is monitored by a thermocouple type $\mathrm{S}$ at a close distance of less than $5 \mathrm{~mm}$ below the samples, which is connected to a digital voltmeter (Keithley DVM 2700, USA). 
The Pt100 at the base of the sample holder is used to monitor the sensor temperature.

The hydration experiments are performed at a RH from $\sim 2 \%$ to $\sim 85 \%$. The RH is controlled by water vapor saturation of air at various temperatures. Ambient air with a constant gas flow of $100 \mathrm{~cm}^{3} \mathrm{~min}^{-1}$ is pumped into a set of impingers. The first one is filled with deionized water to saturate the gas passing through. The second one is empty to prevent water from getting sucked into the measurement setup. Both impingers are placed into a refrigerated/heating bath (Julabo F40-MV, Germany). The water vapor saturated gas flows top down through the sample holder with the samples placed in the direct gas stream for maximized interaction. A humidity sensor (Galltec Type KZC2.H/6, Germany) is integrated in the gas outflow and connected to the digital voltmeter as well.

As the sample and sensor temperature differ slightly by up to a few Kelvin, the measured humidity is corrected with the Magnus relation (Abbott and Tabony, 1985; Alduchov and Eskridge, 1996). Here, the saturation water pressures at sensor $p_{\text {sat }}^{\text {sensor }}$ and sample $p_{\text {sat }}^{\text {sample }}$ are calculated and their quotient is used to correct the humidity sensor data. The general Magnus equation is given by (Magnus, 1844)

$p_{\text {sat }}=c \mathrm{e}^{\frac{a T}{b+T}}$,

with $T$ the temperature given in degrees Celsius and $a, b$ and $c$ coefficients. For this work, the values for these coefficients are taken (Sonntag, 1990), describing the case of small temperature differences near room temperature:

$a=17.62 ; b=243.12^{\circ} \mathrm{C} ; c=611.2 \mathrm{~Pa}$.

The relative humidity at the sample $\mathrm{RH}_{\text {sample }}$ is thus calculated from $\mathrm{RH}_{\text {sensor }}$ by

$\mathrm{RH}=\mathrm{RH}_{\text {sample }}=\frac{p_{\text {sat }}^{\text {sensor }}}{p_{\text {sat }}^{\text {samle }}} \mathrm{RH}_{\text {sensor }}=k \mathrm{RH}_{\text {sensor }}$.

The correction factor $k$ is the relation between saturation vapor pressure at sensor and sample. It simplifies to

$k=\mathrm{e}^{17.62\left(\frac{T_{\text {sensor }}}{243.12^{\circ} \mathrm{C}+T_{\text {sensor }}}-\frac{T_{\text {sample }}}{243.12^{\circ} \mathrm{C}+T_{\text {sample }}}\right)}$.

Sensor and sample temperatures $T_{\text {sensor }}$ and $T_{\text {sample }}$ are taken from the measurements with the thermocouples directly. In the following the saturated water pressure at the sample position is given after correction of the measured humidity.

\subsection{Nanobalance hydration measurements}

The mass change in the SPEEK films is monitored by tracking the resonance frequency of the nanobalance. The latter is done by resonant piezoelectric spectroscopy (RPS), described in detail in the reference (Fritze, 2010). Impedance spectra in the vicinity of the resonance frequency are recorded and used to extract the series resonance frequency. The change in resonance frequency is converted to mass changes according to the Sauerbrey relation (Sauerbrey, 1959; Lucklum and Eichelbaum, 2006; Fritze, 2010; Johannsmann, 2015):

$\Delta m_{\mathrm{RH}}=-A_{\mathrm{eff}} \frac{\Delta f_{\mathrm{R}}}{S_{m}}$.

Here, $\Delta m_{\mathrm{RH}}$ and $\Delta f_{\mathrm{R}}$ are the SPEEK mass change and the detected change in resonance frequency, respectively, due to the incorporation or release of water. $S_{m}$ is the mass sensitivity of the nanobalance. It is defined via the resonance frequency of the unloaded resonator $f_{\mathrm{R}}^{0}$, its thickness $d_{\text {res }}$ and density $\rho_{\text {res: }}$ :

$S_{m}=\frac{f_{\mathrm{R}}^{0}}{d_{\mathrm{res}} \rho_{\mathrm{res}}}$.

For the LGS resonators used in this study, the mass sensitivity near room temperature is about $34.1 \mathrm{~cm}^{2} \mathrm{~Hz} \mathrm{\mu g}^{-1}$. The parameters $f_{\mathrm{R}}^{0}$ and $d_{\mathrm{res}}$ of the respective resonators are measured. The value for the resonator density of $\rho_{\text {res }}=5743.6 \mathrm{~kg} \mathrm{~m}^{-3}$ is taken from Kosinski et al. (2001).

$A_{\text {eff }}$ is the effective electrode area, which is smaller than the geometric electrode area $A_{\mathrm{el}}$. For the resonators in this work $A_{\text {eff }}$ is assumed to be (Fritze, 2010)

$A_{\text {eff }}=0.46 A_{\mathrm{el}}$.

For the given resonators with an electrode diameter of $5.0 \mathrm{~mm}$, this results in a sensitivity $S$ of

$S=\frac{A_{\text {eff }}}{S_{m}}=2.6 \mathrm{ng} \mathrm{Hz}^{-1}$.

Note that the mass $m_{\text {dry }}$ of the dry SPEEK films is also measured in a similar way with high precision by the nanobalance taking the resonance frequency before and after deposition of the SPEEK films. To further increase the sensitivity, a two-step measurement procedure is applied as described in Wulfmeier et al. (2013). The first step monitors the frequency in a broad range, whereas the second step is focused on a narrow range to determine the actual resonance frequency precisely.

\subsection{Proton conductivity measurements}

The proton conductivity of the SPEEK films is measured by electrochemical impedance spectroscopy using an impedance analyzer (Solartron SI 1260, UK) and the interdigitated electrode configuration presented in Fig. 3. To account for expected low conductivities at low RH, a dielectric interface (Solartron SI 1496, UK) is added. The applied alternating current (a.c.) voltage is $50 \mathrm{mV}$ and the frequency 


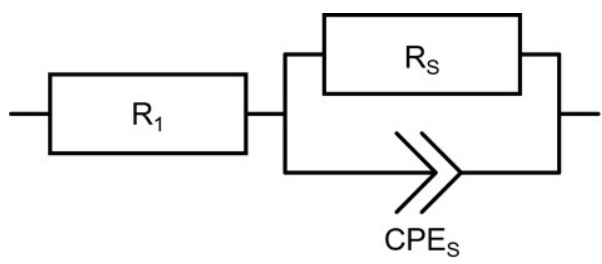

Figure 5. Equivalent circuit diagram for electrochemical impedance spectroscopy.

range between 1 and $10^{7} \mathrm{~Hz}$. The conductivity $\sigma$ is calculated from the Nyquist plots using the following equation:

$\sigma=\frac{d}{L h R_{\mathrm{S}}}$.

Here, $R_{\mathrm{S}}$ is the electrical resistance of the SPEEK film, $d$ the distance between the electrodes filled with SPEEK, $L$ the effective length of the interdigitated electrode (approximately $30 \mathrm{~mm}$ ) and $h$ the thickness of the ionomer film. The equivalent circuit depicted in Fig. 5 is used to fit the data. $R_{1}$ stands for the sum of the lead and electrode resistances. The SPEEK films are represented by the parallel connection of $R_{\mathrm{S}}$ and CPES. A constant phase element (CPE) instead of a pure capacity is chosen to better account for inhomogeneities of the layers (Hirschorn et al., 2010; Macdonald and Johnson, 2005).

\subsection{Measurement sequence}

Prior to the start of the measurement of conductivity and/or hydration, the water vapor saturation of the samples is maximized by setting the bath to $30^{\circ} \mathrm{C}$, which equals the furnace temperature. This condition is maintained for $3 \mathrm{~d}$. During the subsequent measurement, the bath temperature is stepwise cooled down to $4{ }^{\circ} \mathrm{C}$. Each bath temperature and, thus, saturation level is held until the measurement signal from the nanobalance reaches nearly constant values, which takes typically 8 to $12 \mathrm{~h}$. This procedure is repeated until a $\mathrm{RH}$ of about $25 \%$ is reached. For lower RH, the bath is kept at $4{ }^{\circ} \mathrm{C}$, and a further drying is achieved by partially replacing the ambient air by dry argon gas (purity: $99.996 \%$ ). Argon gas flow bypasses the impingers and is led directly into the measurement chamber. The replacement is done stepwise until pure argon flows through the measurement setup. Hereby, the argon flow is kept for $3 \mathrm{~d}$. The state considered in this study to be the dry sample is generated by vacuum drying which is performed with a rotary vane pump (Pfeiffer Duo 10M, Germany). After each evacuation step the measurement chamber is flooded with argon again. The first two cycles are $30 \mathrm{~min}$ each, and the third one lasts $5 \mathrm{~h}$. The humidity sensor shows a minimum of $\mathrm{RH}=2.3 \%$. The value directly after vacuum drying is regarded as the lowest RH step used to calculate $m_{\text {dry }}$. Afterwards, the RH is increased again to its maximum, repeating the described procedure vice versa.

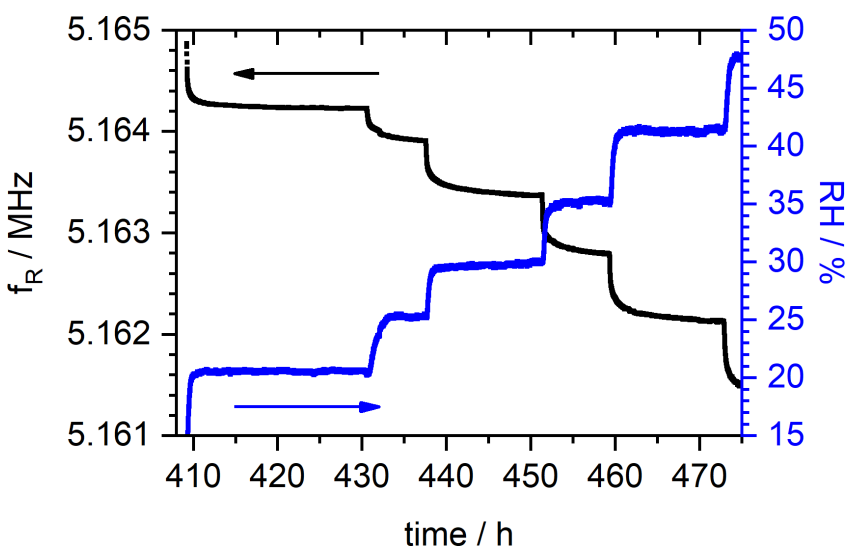

Figure 6. Resonance frequency course $f_{\mathrm{R}}$ and relative humidity (RH) of the SPEEK film with $\mathrm{DS}=0.9$. For means of visibility, the depiction is limited to the measurement time between 409 and $473 \mathrm{~h}$.

\section{Results of the SPEEK hydration measurements}

Relative humidity RH, conductivity $\sigma$, temperature $T$, resonance frequency $f_{\mathrm{R}}$ and, thus, mass change are measured continuously. The resonance frequency and the corresponding relative humidity over time of the sample with $\mathrm{DS}=0.9$ are depicted in Fig. 6. For means of clarity, the presentation is limited to the measurement time between 409 and $473 \mathrm{~h}$ only. In this range, $\mathrm{RH}$ is changed stepwise from about $20 \%$ to $40 \%$. Each next RH level is applied after the resonance frequency shows no significant changes anymore, indicating that the SPEEK film is saturated and in equilibrium with the constant level of water vapor pressure in the surrounding atmosphere. In Fig. 6 it is clearly visible that the measurement velocity is limited by the diffusion kinetics in the SPEEK films as the change in the RH in the atmosphere is significantly faster than the time the corresponding resonance frequency needs to achieve a stationary state. Typically, this equilibrium is reached within 8 to $12 \mathrm{~h}$.

In this work, the resonance frequency $f_{\mathrm{R}}$ is measured once in a minute. This is sufficient to monitor the dynamic of the water uptake by the SPEEK films. For samples with higher activity than SPEEK, the repetition rate of the frequency measurement can be further reduced to only a few seconds.

The equilibrated state is identified for each $\mathrm{RH}$ level and evaluated by calculating the average for $f_{\mathrm{R}}$ and $\mathrm{RH}$ in this region. As an example, the corresponding data range for the humidity step at $\mathrm{RH}=20 \%$ is depicted in Fig. 7. The relative humidity can be set with a precision of about $\pm 0.15 \%$. The precision of the $f_{\mathrm{R}}$ determination is $\Delta f \pm 3.0 \mathrm{~Hz}$ over the $4 \mathrm{~h}$ of measurement time observed. Considering Eq. (8), this equals a mass resolution $R_{m}$ of

$R_{m}=S \Delta f=\frac{A_{\mathrm{eff}}}{S_{m}} \Delta f= \pm 7.9 \mathrm{ng}$. 


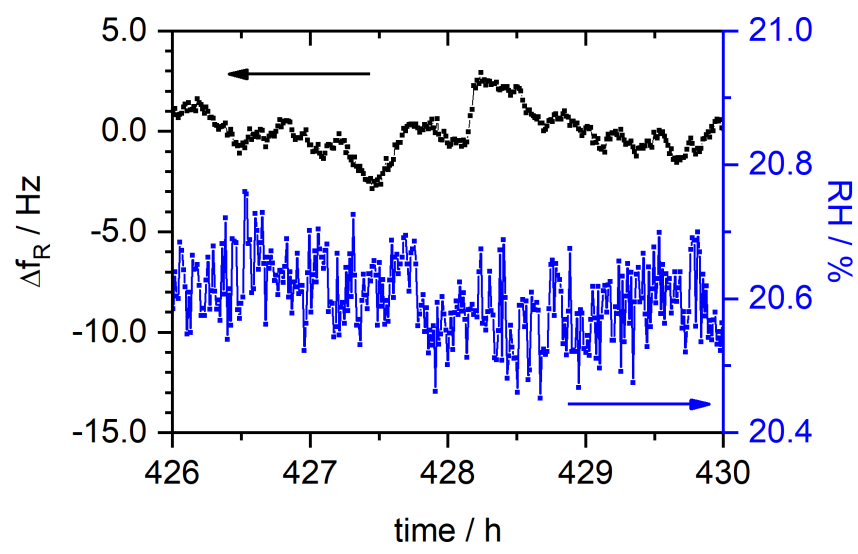

Figure 7. Resonance frequency $f_{\mathrm{R}}$ and RH of the SPEEK film with $\mathrm{DS}=0.9$ in an equilibrated state as it is used to determine the mass change at each RH level. The data shown in this graph are an augmentation of the corresponding segment shown in Fig. 6.

As described before, the resonance frequency change is converted to a mass change. The latter is equal to the WU:

$\mathrm{WU} / \%=\frac{m_{\mathrm{RH}}-m_{\mathrm{dry}}}{m_{\mathrm{dry}}} \cdot 100=\frac{\Delta m_{\mathrm{RH}}}{m_{\mathrm{dry}}} \cdot 100$,

with $m_{\mathrm{RH}}$ the mass of the SPEEK film as calculated by Eq. (5).

The hydration number $\lambda$ can be calculated using the following equation:

$\lambda=\frac{\mathrm{WU} \cdot 10}{\mathrm{IEC} \cdot M\left(\mathrm{H}_{2} \mathrm{O}\right)}$.

$M\left(\mathrm{H}_{2} \mathrm{O}\right)$ and IEC are the molar mass of water and the ion exchange capacity, respectively. The IEC values for SPEEK are 2.5 and $1.5 \mathrm{meq}^{-1}$ for $\mathrm{DS}=0.9$ and $\mathrm{DS}=0.5$, respectively.

Figures 8 and 9 show the hydration numbers $\lambda$ calculated according to Eq. (12) and the proton conductivities $\sigma$ in logarithmic representation for SPEEK with DS values of 0.9 and 0.5 , respectively. The water incorporation of the hydrated sample with a DS of 0.9 at the start of the measurement equals $27 \%$ of the dry SPEEK mass. After drying the sample, a rehydration with a WU of $22 \%$ is seen. For SPEEK with a DS of 0.5 , the absolute values of the WU are lower at $14 \%$ and $13 \%$ before and after drying. However, it should be mentioned that the difference in WU between the initial and final conditions appears to be too small, since a higher $\mathrm{RH}$ could be realized in the measurement setup during rehydration than at the start of the measurement.

The hydration numbers for SPEEK 0.9 in Fig. 8 are higher than previous hydration experiments in humid atmospheres obtained by thermogravimetric analysis (Di Vona et al., 2009). The figures show the typical hysteresis between data obtained by decreasing and then increasing the RH. This hysteresis is well known in porous materials (hysteresis loop type H3 in the IUPAC classification; Thommes et

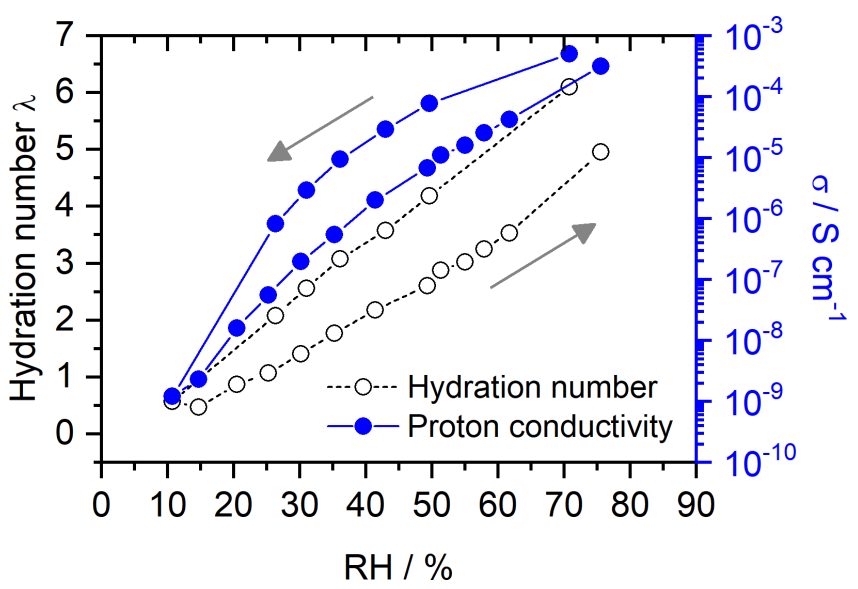

Figure 8. Hydration number $\lambda$ and proton conductivity $\sigma$ of SPEEK $(\mathrm{DS}=0.9)$ at $30^{\circ} \mathrm{C}$.

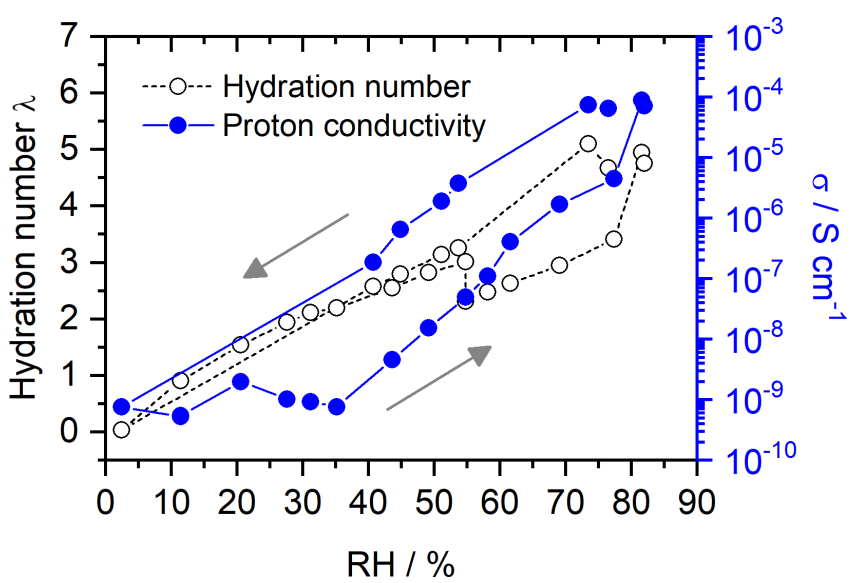

Figure 9. Hydration number $\lambda$ and proton conductivity $\sigma$ of SPEEK $(\mathrm{DS}=0.5)$ at $30^{\circ} \mathrm{C}$.

al., 2015) and is related to the fact that initially capillary effects contribute to the water uptake at high $\mathrm{RH}$, whereas on rehydration from very low RH capillary effects are absent. There is an obvious relation between the hydration and the ionic conductivity, which is expected in materials, where the ionic migration proceeds inside hydrated nanometric channels (Di Vona et al., 2013; Knauth et al., 2011).

For SPEEK DS $=0.5$ (Fig. 9), there is no hysteresis at RH below $40 \%$, probably due to the much lower water affinity of the ionomer given its low sulfonic acid content. Accordingly, the hydration numbers $(<5)$ and proton conductivities are much lower than those of SPEEK DS $=0.9$.

\section{Conclusions}

A newly developed experimental setup to characterize thin polymeric films during dehydration and hydration is presented. The great advantage of this measurement device and technique is that it monitors the mass change and conduc- 
tivity of the films in situ and simultaneously under virtually identical conditions. The feasibility of the technique is demonstrated by characterizing ionomer thin films. Here, a mass resolution of $\pm 7.9 \mathrm{ng}$ is achieved. The precision of $\mathrm{RH}$ control is $\pm 0.15 \%$. Currently the system is limited to a relative humidity of $85 \%$ and below. This limit can be overcome by e.g. a heated gas transfer line.

SPEEK films with varying degrees of sulfonation are used as the model system. Their hydration is characterized over a wide range of $\mathrm{RH}$ in the surrounding atmosphere. A decrease in conductivity of about 6 orders of magnitude is detected when changing the atmosphere from $\sim 80 \% \mathrm{RH}$ to nearly $0 \% \mathrm{RH}$, which is in agreement with values reported in the literature. The simultaneously detected water uptake equals $\sim 27 \%(\mathrm{DS}=0.9)$ and $\sim 14 \%(\mathrm{DS}=0.5)$ of the dry SPEEK mass.

The results show the feasibility of the new in situ sensor system and its potential for assisting material development in the field of polymeric ion-conducting thin films. The data obtained by this measurement approach can be used to either identify conditions of best material performance or to avoid application conditions leading to a degradation and malfunction of devices using these materials.

Data availability. The data presented in this article are stored in an internal system according to the guidelines of the German Research Foundation (Deutsche Forschungsgemeinschaft; DFG). Research data are available upon request to the authors.

Author contributions. LP synthesized the initial SPEEK polymers and characterized these. HW and HF designed and configured the measurement setup. HW and NW were responsible for the resonator preparation and the film deposition. Both performed the in situ characterization of hydration and ionic conductivity and analyzed the data. HF and PK initiated and led the research project. All the authors contributed to data interpretation and discussion. HW, $\mathrm{HF}$ and PK wrote and approved the final paper.

Competing interests. The contact author has declared that neither they nor their co-authors have any competing interests.

Disclaimer. Publisher's note: Copernicus Publications remains neutral with regard to jurisdictional claims in published maps and institutional affiliations.

Acknowledgements. In addition, the authors thank the Research Center Energy Storage Technologies (Forschungszentrum Energiespeichertechnologien) for supporting this work.
Financial support. The authors were financially supported by the DFG (grant nos. FR 1301/35-01 and FR 1301/20-02).

This open-access publication was funded

by Clausthal University of Technology.

Review statement. This paper was edited by Bernhard Jakoby and reviewed by two anonymous referees.

\section{References}

Abbott, P. and Tabony, R.: The estimation of humidity parameters, Meterol. Mag., 114, 49-56, 1985.

Alberti, G. and Casciola, M.: Solid state protonic conductors, present main applications and future prospects, Solid State Ionics, 145, 3-16, https://doi.org/10.1016/S0167-2738(01)00911-0, 2001.

Alberti, G. and Casciola, M.: Composite membranes for mediumtemperature PEM fuel cells, Annu. Rev. Mater. Res., 33, 129154, https://doi.org/10.1146/annurev.matsci.33.022702.154702, 2003.

Alberti, G., Casciola, M., Massinelli, L., and Bauer, B.: Polymeric proton conducting membranes for medium temperature fuel cells $\left(110-160^{\circ} \mathrm{C}\right)$, J. Membrane Sci., 185, 73-81, https://doi.org/10.1016/S0376-7388(00)00635-9, 2001.

Alberti, G., Narducci, R., and Sganappa, M.: Effects of hydrothermal/thermal treatments on the water-uptake of Nafion membranes and relations with changes of conformation, counterelastic force and tensile modulus of the matrix, J. Power Sources, 178, 575-583, https://doi.org/10.1016/j.jpowsour.2007.09.034, 2008.

Alduchov, O. A. and Eskridge, R. E.: Improved Magnus form approximation of saturation vapor pressure, J. Appl. Meteorol., 35, 601-609, https://doi.org/10.1175/15200450(1996)035<0601:IMFAOS>2.0.CO;2, 1996.

Arges, C. G. and Zhang, L.: Anion exchange membranes' evolution toward high hydroxide ion conductivity and alkaline resiliency, ACS Applied Energy Materials, 1, 2991-3012, https://doi.org/10.1021/acsaem.8b00387, 2018.

Bauer, B., Strathmann, H., and Effenberger, F.: Anion-exchange membranes with improved alkaline stability, Desalination, 79, 125-144, https://doi.org/10.1016/0011-9164(90)85002-R, 1990.

Bauer, B., Jones, D. J., Roziere, J., Tchicaya, L., Alberti, G., Casciola, M., Massinelli, L., Peraio, A., Besse, S., and Ramunni, E.: Electrochemical characterisation of sulfonated polyetherketone membranes, J. New Mat. Elect. Syst., 3, 93-98, 2000.

Casciola, M., Alberti, G., Sganappa, M., and Narducci, R.: On the decay of Nafion proton conductivity at high temperature and relative humidity, J. Power Sources, 162, 141-145, https://doi.org/10.1016/j.jpowsour.2006.06.023, 2006.

Couture, G., Alaaeddine, A., Boschet, F., and Ameduri, B.: Polymeric materials as anion-exchange membranes for alkaline fuel cells, Prog. Polym. Sci., 36, 1521-1557, https://doi.org/10.1016/j.progpolymsci.2011.04.004, 2011.

Czanderna, A. W. and Lu, C: Introduction, history, and overview of applications of piezoelectric quartz crystal microbalances, in: Applications of piezoelectric quartz crystal microbalances, 
edited by: Lu, C. and Czanderna, A. W., Elsevier B. V., Amsterdam, 1-18, https://doi.org/10.1016/B978-0-444-42277-4.500077, 1984.

Di Vona, M. L., Ahmed, Z., Bellitto, S., Lenci, A., Traversa, E., and Licoccia, S.: SPEEK-TiO 2 nanocomposite hybrid proton conductive membranes via in situ mixed sol-gel process, J. Membrane Sci., 296, 156-161, https://doi.org/10.1016/j.memsci.2007.03.037, 2007.

Di Vona, M. L., Licoccia, S., and Knauth, P.: Organicinorganic hybrid membranes based on sulfonated polyarylether-ketones: Correlation between water uptake and electrical conductivity, Solid State Ionics, 179, 1161-1165, https://doi.org/10.1016/j.ssi.2008.01.012, 2008a.

Di Vona, M. L., Sgreccia, E., Licoccia, S., Khadhraoui, M., Denoyel, R., and Knauth, P.: Composite proton-conducting hybrid polymers: Water sorption isotherms and mechanical properties of blends of sulfonated PEEK and substituted PPSU, Chem. Mater., 20, 4327-4334, https://doi.org/10.1021/cm800155r, 2008b.

Di Vona, M. L., Sgreccia, E., Licoccia, S., Alberti, G., Tortet, L., and Knauth, P.: Analysis of Temperature-Promoted and SolventAssisted Cross-Linking in Sulfonated Poly(ether ether ketone) (SPEEK) Proton-Conducting Membranes, J. Phys. Chem. B, 113, 7505-7512, https://doi.org/10.1021/jp9006679, 2009.

Di Vona, M. L., Pasquini, L., Narducci, R., Pelzer, K., Donnadio, A., Casciola, M., and Knauth, P.: Cross-linked sulfonated aromatic ionomers via $\mathrm{SO}_{2}$ bridges: Conductivity properties, J. Power Sources, 243, 488-493, https://doi.org/10.1016/j.jpowsour.2013.05.127, 2013.

Eikerling, M. H. and Berg, P.: Poroelectroelastic theory of water sorption and swelling in polymer electrolyte membranes, Soft Matter, 7, 5976-5990, https://doi.org/10.1039/C1SM05273J, 2011.

Elattar, A., Elmidaoui, A., Pismenskaia, N., Gavach, C., and Pourcelly, G.: Comparison of transport properties of monovalent anions through anion-exchange membranes, J. Membrane Sci., 143, 249-261, https://doi.org/10.1016/S0376-7388(98)00013-1, 1998.

Freger, V.: Hydration of ionomers and Schroeder's paradox in Nafion, J. Phys. Chem. B, 113, 24-36, https://doi.org/10.1021/jp806326a, 2009.

Fritze, H.: High-temperature bulk acoustic wave sensors, Meas. Sci. Technol., 22, 012002-012030, https://doi.org/10.1088/09570233/22/1/012002, 2010.

Fritze, H. and Tuller, H. L.: High-Temperature Balance, U.S. Patent No. 6.370.955, https://patft.uspto.gov/netacgi/nph-Parser? Sect $1=$ PTO $1 \&$ Sect $2=$ HITOFF $\& d=P A L L \& p=1 \& \mathrm{u}=/$ netahtml $/$ $\mathrm{PTO} /$ srchnum.htm \&r=1\&f=G\&l=50\&s1=6370955.PN.\&OS= PN/6370955\&RS=PN/6370955 (last access: 17 February 2022), 2002.

Grate, J. W.: Acoustic wave microsensor arrays for vapor sensing, Chem. Rev., 100, 2627-2648, https://doi.org/10.1021/cr980094j, 2000.

Habuka, H. and Tanaka, Y.: In-situ monitoring of chemical vapor deposition from trichlorosilane gas and monomethylsilane gas using langasite crystal microbalance, Journal of Surface Engineered Materials and Advanced Technology, 3, 61-66, https://doi.org/10.4236/jsemat.2013.31A009, 2013.

Hirschorn, B., Orazem, M. E., Tribollet, B., Vivier, V., Frateur, I., and Musiani, M.: Determination of effec- tive capacitance and film thickness from constant-phaseelement parameters, Electrochim. Ac., 55, 6218-6227, https://doi.org/10.1016/J.ELECTACTA.2009.10.065, 2010.

Johannsmann, D.: The quartz crystal microbalance in soft matter research - fundamentals and modelling, Springer International Publishing Switzerland, Cham, 5-9, https://doi.org/10.1007/9783-319-07836-6, 2015.

Jones, D. J. and Roziere, J.: Recent advances in the functionalisation of polybenzimidazole and polyetherketone for fuel cell applications, J. Membrane Sci., 185, 41-58, https://doi.org/10.1016/S0376-7388(00)00633-5, 2001.

Kaliaguine, S., Mikhailenko, S. D., Wang, K. P., Xing, P., Robertson, G., and Guiver, M.: Properties of SPEEK based PEMs for fuel cell application, Catal. Today, 82, 213-222, https://doi.org/10.1016/S0920-5861(03)00235-9, 2003.

Kerres, J. A.: Development of ionomer membranes for fuel cells, J. Membrane Sci., 185, 3-27, https://doi.org/10.1016/S03767388(00)00631-1, 2001.

Knauth, P. and Di Vona, M. L.: Sulfonated aromatic ionomers: Analysis of proton conductivity and proton mobility, Solid State Ionics, 225, 255-259, https://doi.org/10.1016/j.ssi.2012.01.043, 2012.

Knauth, P., Sgreccia, E., Donnadio, A., Casciola, M., and Di Vona, M. L.: Water activity coefficient and proton mobility in hydrated acidic polymers, J. Electrochem. Soc., 158, B159-B165, https://doi.org/10.1149/1.3515321, 2011.

Knauth, P., Pasquini, L., Narducci, R., Sgreccia, E., BecerraArciniegas, R. A., and Di Vona, M. L.: Effective ion mobility in anion exchange ionomers: Relations with hydration, porosity, tortuosity, and percolation, J. Membrane Sci., 617, 118622 , https://doi.org/10.1016/j.memsci.2020.118622, 2021.

Kopitzke, R. W., Linkous, C. A., Anderson, H. R., and Nelson, G. L.: Conductivity and water uptake of aromatic-based proton exchange membrane electrolytes, J. Electrochem. Soc., 147, 16771681, https://doi.org/10.1149/1.1393417, 2000.

Kosinski, J. A., Jr. Pastore, R. A., Bigler, E., Pereira da Cunha, M., Malocha, D. C., and Detaint, J.: A review of langasite material constants from BAW and SAW data: Toward an improved data set, Proceedings of the 2001 IEEE International Frequency Control Symposium, 2001, 278-286, https://doi.org/10.1109/FREQ.2001.956203, 2001.

Kreuer, K. D.: On the development of proton conducting materials for technological applications, Solid State Ionics, 97, 1-15, https://doi.org/10.1016/S0167-2738(97)00082-9, 1997.

Kreuer, K. D.: The role of internal pressure for the hydration and transport properties of ionomers and polyelectrolytes, Solid State Ionics, 252, 93-101, https://doi.org/10.1016/j.ssi.2013.04.018, 2013.

Kreuer, K. D., Paddison, S. J., Spohr, E., and Schuster, M.: Transport in proton conductors for fuel-cell applications: Simulations, elementary reactions, and phenomenology, Chem. Rev., 104, 4637-4678, https://doi.org/10.1021/cr020715f, 2004.

Leppin, C., Langhoff, A., Höfft, O., and Johannsmann, D.: A modulation QCM applied to copper electrodeposition and stripping, Electroanalysis, 33, 2529-2538, https://doi.org/10.1002/elan.202100471, 2021.

Li, Q. F., He, R. H., Jensen, J. O., and Bjerrum, N. J.: Approaches and recent development of polymer electrolyte membranes for 
fuel cells operating above $100^{\circ} \mathrm{C}$, Chem. Mater., 15, 4896-4915, https://doi.org/10.1021/cm0310519, 2003.

Lucklum, R. and Eichelbaum, F.: Interface circuits for QCM sensors, in: Piezoelectric sensors. Springer series on chemical sensors and biosensors (methods and applications), vol. 5, edited by: Janshoff, A. and Steinem, C., Springer, Berlin, Heidelberg, https://doi.org/10.1007/978-3-540-36568-6_1, 2006.

Macdonald, J. R. and Johnson, W. B.: Fundamentals of impedance spectroscopy, in: Impedance spectroscopy - Theory, experiment, and applications, 2nd ed., edited by: Barsoukov, E. and Macdonald, J. R., John Wiley \& Sons Inc., Hoboken, NJ, USA, 1-26, https://doi.org/10.1002/0471716243, 2005.

Magnus, G.: Versuche über die Spannkräfte des Wasserdampfes, Annalen der Physik und Chemie, Band LXI Nr. 2, , 225-248, https://doi.org/10.1002/andp.18441370202, 1844.

Maier, G. and Meier-Haack, J.: Sulfonated aromatic polymers for fuel cell membranes, in: Fuel cells II, Advanced polymer science, Vol. 216, edited by: Scherer, G. G., Springer-Verlag, Berlin, Deutschland, 1-62, https://doi.org/10.1007/12_2008_135, 2008.

Marx, K. A.: The quartz crystal microbalance and the electrochemical QCM: Applications to studies of thin polymer films, electron transfer systems, biological macromolecules, biosensors, and cells, in: Piezoelectric sensors. Springer series on chemical sensors and biosensors (methods and applications), vol. 5, edited by: Janshoff, A. and Steinem, C., Springer, Berlin, Heidelberg, https://doi.org/10.1007/978-3-540-36568-6_11, 2006.

Mehta, V. and Cooper, J. S.: Review and analysis of PEM fuel cell design and manufacturing, J. Power Sources, 114, 32-53, https://doi.org/10.1016/S0378-7753(02)00542-6, 2003.

Pascal-Delannoy, F., Sorli, B., and Boyer, A.: Quartz crystal microbalance (QCM) used as humidity sensor, Sensor. Actuators A-Phys., 84, 285-291, https://doi.org/10.1016/S09244247(00)00391-5, 2000

Peckham, T. J., Schmeissert, J., and Holdcroft, S.: Relationships of acid and water content to proton transport in statistically sulfonated proton exchange membranes: Variation of water content via control of relative humidity, J. Phys. Chem. B, 112, 28482858, https://doi.org/10.1021/jp077218t, 2008.

Ruzimuradov, O., Braglia, M., Vacandio, F., and Knauth, P.: A humidity-sensitive nanocomposite solid ion conductor: sulfonated poly-ether-ether-ketone in nanotubular $\mathrm{TiO}_{2}$ or $\mathrm{ZrO}_{2}$ matrix, J. Solid State Electr., 22, 3255-3260, https://doi.org/10.1007/s10008-018-4026-8, 2018.

Sauerbrey, G.: Verwendung von Schwingquarzen zur Wägung dünner Schichten und Mikrowagen, Z. Phys., 155, 206-222, https://doi.org/10.1007/BF01337937, 1959.

Schröder, S., Fritze, H., Bishop, S., Chen, D., and Tuller, H. L.: Thin-film thermogravimetry applied to praseodymium-cerium oxide films at high temperatures, Appl. Phys. Lett., 112, 213502, https://doi.org/10.1063/1.5025389, 2018.
Seh, H., Fritze, H., and Tuller, H. L.: Defect chemistry of langasite III: Predictions of electrical and gravimetric properties and application to operation of high temperature crystal microbalance, J. Electroceram., 18, 139-147, https://doi.org/10.1007/s10832007-9016-7, 2007.

Sonntag, D.: Important new values of physical constants of vapor pressure formulations based on ITS-90 and psychrometer formulae, Z. Meterol., 70, 340-344, 1990.

Sun, Z., Lin, B. C., and Yan, F.: Anion-exchange membranes for alkaline fuel-cell applications: The effects of cations, ChemSusChem, 11, 58-70, https://doi.org/10.1002/CSSC.201701600, 2018.

Thommes, M., Kaneko, K., Neimark, A. V., Olivier, J. P., Rodriguez-Reinoso, F., Rouquerol, J., and Sing, K. S. W.: Physisorption of gases, with special reference to the evaluation of surface area and pore size distribution (IUPAC Technical Report), Pure Appl. Chem., 87, 1051-1069, https://doi.org/10.1515/pac-2014-1117, 2015.

Varcoe, J. R. and Slade, R. C. T.: Prospects for alkaline anionexchange membranes in low temperature fuel cells, Fuel Cells, 5, 187-200, https://doi.org/10.1002/fuce.200400045, 2005.

Varcoe, J. R., Atanassov, P., Dekel, D. R., Herring, A. M., Hickner, M. A., Kohl, P. A., Kucernak, A. R., Mustain, W. E., Nijmeijer, K., Scott, K., Xu, T. W., and Zhuang, L.: Anion-exchange membranes in electrochemical energy systems, Energ. Environ. Sci., 7, 3135-3191, https://doi.org/10.1039/C4EE01303D, 2014.

Wulfmeier, H., Albrecht, D., Ivanov, I., Fischer, J., Ulrich, S., Bund, A., and Fritze, H.: High-temperature thin-film calorimetry: A newly developed method applied to lithium ion battery materials, J. Mater. Sci., 48, 6585-6596, https://doi.org/10.1007/S10853013-7455-X, 2013.

Xing, P. X., Robertson, G. P., Guiver, M. D., Mikhailenko, S. D., Wang, K. P., and Kaliaguine, S.: Synthesis and characterization of sulfonated poly(ether ether ketone) for proton exchange membranes, J. Membrane Sci., 229, 95-106, https://doi.org/10.1016/J.MEMSCI.2003.09.019, 2004.

Zawodzinski, T. A., Springer, T. E., Davey, J., Jestel, R., Lopez, C., Valerio, J., and Gottesfeld, S.: A comparative study of water-uptake by and transport through ionomeric fuel-cell membranes, J. Electrochem. Soc., 140, 1981-1985, https://doi.org/10.1149/1.2220749, 1993.

Zhong, S. L., Cui, X. J., Cai, H. L., Fu, T. Z., Zhao, C., and $\mathrm{Na}, \mathrm{H} .:$ Crosslinked sulfonated poly(ether ether ketone) proton exchange membranes for direct methanol fuel cell applications, J. Power Sources, 164, 65-72, https://doi.org/10.1016/j.jpowsour.2006.10.077, 2007. 